\title{
Healing complications of dental extraction performed with and without sterile gloves
}

\author{
Sudeep Acharya ${ }^{1}$, Sandhya Joshi, ${ }^{2}$ Surendra Acharya ${ }^{1}$ \\ ${ }^{1}$ Department of Oral and Maxillofacial Surgery, KIST Medical College \\ ${ }^{2}$ National Trauma Center (NAMS)
}

Correspondence: Dr. Sudeep Acharya, MDS, Associate Professor, Department of Oral and Maxillofacial Surgery, KIST Medical College

Email: drsudeepacharya@gmail.com

\begin{abstract}
Introduction: Dental extractions are usually carried out in non-sterile environment using clean non-sterile gloves. However, the use of non-sterile gloves are frequently probed for post surgical socket healing complications. Hence it is necessary to gather clinical proofs to answer this query. The present study aimed to compare healing complications of dental extraction performed with and without sterile gloves.

Methods: The study design was comparative cross-sectional. The sample size was calculated as 51 per group. The patients were randomly allocated to either group by allowing them to choose a lottery. All the patients undergoing non surgical dental extraction constituted the study population for present study. History taking and observation technique was used to collect data. The proforma was prepared and filled up by the researcher.

Results: Four (7.8\%) cases in clean sterile group and 3 (5.9\%) cases in surgical gloves group had some complications. The difference in presence of complications across groups was not significant.

Conclusion: The non-sterile clean gloves do not increase the incidence of postoperative complications as compared to sterile gloves.
\end{abstract}

Key words: Socket healing complications; Sterile gloves; Tooth extraction.

\section{Introduction}

Sterile gloves are meant for maintaining sterility during surgeries for prevention of post surgical infections. Dental extraction even done with bare hands had evidenced minimal risk of infections. ${ }^{1}$ Dental extraction even though a surgical procedure, is normally performed in a surgically clean but non-sterile environment. ${ }^{2}$ At one hand, this creates a confusion among dental surgeons about the choice of the gloves for this procedure and on the other hand looking at increasing budget of dental services, the use of sterile gloves has been an emerging question.

Non-surgical dental extractions are usually executed using clean non-sterile gloves but the use of non-sterile gloves are often questioned for post surgical socket healing complications. Hence it is necessary to gather clinical proofs to answer this query. ${ }^{2}$ Thus this study can be an eye opener over the issue of a sterile vs non-sterile gloves in country like Nepal where cost of treatment is always an issue to the patient and to the management whereas lower infection rate is always anticipated. The objective of this study was to compare healing complications of dental extraction performed with and without sterile gloves.

\section{Methods}

The study design was comparative cross-sectional. The sample size was calculated using $\mathrm{G}^{*}$ Power 3.1 software. $^{3}$ This study enrolled 102 patients attending oral surgery 
outpatient department (OPD). The sample size was calculated as 51 per group assuming medium effect size of 0.5 of complication rate between sterile gloves and clean non-sterile gloves group at $80 \%$ power and 5\% level of significance. The patients were randomly allocated to either group by allowing them to choose a lottery. The researcher prepared 102 chits written 'sterile' and 'nonsterile' on 51 each. Then, they were kept in a small paper box. As a patient, fulfilling inclusion criteria, was presented at the Oral Surgery OPD, the patient was offered to choose a lottery. All the patients undergoing non-surgical dental extraction constituted the study population for present study.

History taking and observation technique was used to collect data. The proforma was prepared and filled up by the researchers. Patients were followed up on next day and $7^{\text {th }}$ day of extraction to assess the healing complications. The patients with diabetes mellitus (DM), severe nutritional deficiencies, endocrine disturbances, preoperative gingival index of Loe and Silness greater than 1 , history of radiotherapy for the treatment of head and neck malignancies; patients on oral contraceptives, steroids and antibiotics for an existing infections were excluded from the study. Smokers and alcohol consumers were not included in the study. The data were coded and entered in SPSS 16. The data was analyzed using descriptive statistics and chi-square test.

The ethical approval was obtained from KIST Medical College Institution Review Committee. The participants were informed about the objectives of the study and written informed consent were obtained from each participant.

\section{Results}

The mean age of the patients was 41.4 years with standard deviation (SD) 15.9. There were 43 (42.2\%) male and 59 $(57.8 \%)$ female patients.

Among individuals in clean non-sterile gloves group, $39(76.5 \%)$ had single and $12(23.5 \%)$ had multiple tooth extractions. In sterile gloves group, 44(86.3\%) and 7(13.7\%) had single and multiple tooth extractions respectively. Among cases in clean non-sterile group, 41(80.4\%) had procedure performed on posterior, $8(15.7 \%)$ on anterior and $2(3.9 \%)$ on both sites where as among cases in sterile gloves group, $50(98 \%)$ on posterior and $1(2 \%)$ on both sites. In clean non-sterile gloves group, 18(35.3\%) cases had $3^{\text {rd }}$ quadrant involved followed by other quadrants. In sterile gloves group, 21(41.2\%) were $4^{\text {th }}$ quadrant tooth extraction followed by others. Few cases involved multiple quadrants. (Table 1)
Table 1. Tooth extraction details in both group

$\begin{array}{llll}\text { Extraction details } & \begin{array}{l}\text { Clean } \\ \text { non-sterile } \\ \text { gloves }\end{array} & \text { Sterile gloves } \\ \text { Tooth extraction } & \text { Single } & 39(76.5) & 44(86.3) \\ & \text { Multiple } & 12(23.5) & 7(13.7) \\ \text { Site } & \text { Anterior } & 8(15.7) & 0 \\ & \text { Posterior } & 41(80.4) & 50(98) \\ \text { Quadrant } & \text { Both } & 2(3.9) & 1(2) \\ & 1^{\text {st }} & 9(17.6) & 13(25.5) \\ & 2^{\text {nd }} & 12(23.5) & 5(9.8) \\ & 3^{\text {rd }} & 18(35.3) & 10(19.6) \\ & 4^{\text {th }} & 11(21.6) & 21(41.2) \\ & 1^{\text {st }} \text { and } 4^{\text {th }} & 0 & 2(3.9) \\ & 1^{\text {st }} \text { and } 2^{\text {nd }} & 1(1.9) & 0\end{array}$

Table 2. Type of complications in both group

$\begin{array}{lll}\text { Type of complications } & \begin{array}{l}\text { Clean non-sterile Sterile gloves } \\ \text { gloves }\end{array} \\ \text { Dry socket } & 2(3.9) & 1(2) \\ \text { Acutely inflamed socket } & 2(3.9) & 2(3.9) \\ \text { No complication } & 47(92.2) & 48(94.1)\end{array}$

Majority of cases did not have any complications following the procedure in both groups. Few cases had dry socket and acutely inflamed socket in both groups. (Table 2)

Four $(7.8 \%)$ cases in clean non-sterile gloves group and $3(5.9 \%)$ cases in sterile gloves group had some complications. The difference in presence of complications across groups was not significant (chi square $=0.153$, $\mathrm{p}=0.695)$.

\section{Discussion}

Dental treatment is always considered to be expensive. The diversity in treatment includes minor scaling to major oral surgical procedures. In country like Nepal, where people are less likely to attend dental treatment due to its cost factor and awareness, there is always a need to reduce cost to promote oral health of patients. Using clean gloves can 
be one of the mode to minimize cost of the treatment. The cost of the dental extraction performed with surgical gloves in a teaching institute is even more debatable issue. Voices has always been raised over the use of surgical gloves to do dental extraction in low cost and in an unsterile environment (oral cavity). As evidences suggest, the use of sterile gloves do not prove less infection and complications following dental extraction. ${ }^{1,2,4,5}$ It has been conferred that postoperative infections were not observed in either groups who underwent removal of erupted teeth with use of sterile gloves and clean non-sterile gloves. ${ }^{4}$ Sterility of gloves have no influence on preventing bidirectional transmission of communicable diseases. ${ }^{6}$ Hence, use of such gloves while doing intra-oral procedures, concerned only about incidence of postoperative infection. ${ }^{6}$ Even though, clean gloves are used for dental extractions, all the procedures must be performed with complete sterile instruments since there are chances of transmission of blood/body-fluid borne organisms. All the instruments to be used in oral cavity needs to be sterile owing to risks of various communicable diseases. Any dental procedures can be traumatic thereby having mucosal tear or lacerations, it is recommended that all the instruments should be completely sterile and all standard /universal precautions to be followed for all the intraoral procedures to be performed in oral cavity.

The American Dental Association back in 1978, recommended to wear gloves during examination and intraoral surgical procedures. $^{2}$ They further explained that The American Centers for Disease Control (CDC) guidelines instruct to use nonsterile gloves for examinations and nonsurgical procedures, and sterile gloves for surgical procedures. They have argued that though dental extraction is a surgical procedure, it is conducted in unsterile environment, hence posing a dilemma to the practitioners on choosing sterile or unsterile gloves. They showed that $8.8 \%$ in non-sterile gloves group as compared to $15.6 \%$ in sterile gloves group developed socket healing complications which is statistically insignificant $(\mathrm{p}=0.09) .{ }^{2}$ A comparison of post operative complications following wisdom tooth surgery performed with sterile or clean gloves showed that there were $9.5 \%$ and $13.8 \%$ socket healing complications in sterile and non-sterile clean gloves group respectively. ${ }^{5}$ It had been a common practice to use surgical rubber gloves in operation theatres by early 1900 s, however in 80 s, universal precautions had been institutionalized to battle the spread of HIV and hepatitis. ${ }^{7}$ The use of surgical gloves did not minimize the rate of postoperative infections as compared to examination gloves following minor surgical procedures and hence examination gloves could be used for minor surgical procedures without increasing the risk of postoperative infections. ${ }^{7}$
Present study showed similar results of non-significant differences in socket healing complication following dental extraction using sterile and clean non-sterile gloves. The dentist can perform non-surgical dental extraction safely using surgically clean gloves without post operative infections. But it's always safe and advisable to use sterile gloves if budget is not an issue.

\section{References}

1. Cheung LK, Chow LK, Tsang MH, Tung LK. An evaluation of complications following dental extractions using either sterile or clean gloves. Int. J. Oral Maxillofac. Surg. 2001; 30: 550-554.

2. Adeyemo WL, Ogunlewe MO, Ladeinde AL, Bamgbose BO. Are Sterile Gloves Necessary in Nonsurgical Dental Extractions? J Oral Maxillofac Surg. 2005; 63:936-940.

3. Faul, F, Erdfelder, E, Lang, AG, Buchner A. G*Power 3: A flexible statistical power analysis program for the social, behavioral, and biomedical sciences. Behavior Research Methods. 2007; 39: 175-191.

4. Giglio JA, Rowland RW, Laskin DM, Grenevicki L, Roland RW The use of sterile versus nonsterile gloves during out-patient exodontia. Quintessence Int. 1995; 26(8):533.

5. Chiu WK, Cheung LK, Chan HC, Chow LK. A comparison of post operative complications following wisdom tooth surgery performed with sterile or clean gloves. Int. J. Oral Maxillofac. Surg. 2006; 35: 174179.

6. Laskin DM. The selection of proper gloves for intraoral surgery(editorial). J Oral Maxillofac Surg. $1999 ; 57: 887$.

7. Das P, Nayyar AS, Haridas O, Sirisha K L, Karan A, Pramod K. Relevance of surgical gloves in minor surgical procedures in the present scenario: A randomized, double-blind, controlled trial. Int $\mathrm{J}$ Clinicopathol Correl. 2017;1:1-6. 